\title{
El inglés y el español en contacto en los Estados Unidos. Reflexiones acerca de los retos, dilemas y complejidad de la situación sociolingüística estadounidense
}

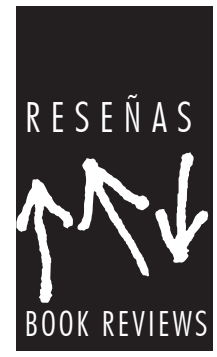

Silvia Betti y Renata Enghels (eds). 2020. Canterano: Aracne. 148 pp.

\section{Reseña de Isaac Galassi}

El presente monográfico, editado por Silvia Betti, profesora de la Universidad de Bolonia y miembro de la Academia Norteamericana de la Lengua Española, y Renata Enghels, profesora de la Universidad de Gante, ofrece un conjunto de 8 artículos resultantes del trabajo de 14 investigadores de Norteamérica y Europa, quienes presentan el estado de la cuestión del contacto del español y el inglés en Estados Unidos. Gracias a la diversidad de las áreas de estudio de estos autores y autoras, el volumen cuenta con distintas visiones que permiten estudiar el contacto inglés/español desde distintas aristas. El monográfico se divide en dos partes: una primera que aborda los aspectos sociales, identitarios y políticos del español, y una segunda centrada en el uso, la gramática y la psicolingüística del spanglish.

El prólogo, escrito por Domnita Dumitrescu, invita a considerar la relevancia del estudio científico del español en el ambiente particularmente represivo que implica la presidencia de Trump, y apunta a la oportunidad y al dilema que representa la investigación del fenómeno de contacto para los sociolingüistas. Luego, la introducción de Silvia Betti enmarca al español desde su peculiaridad lingüística y cultural, y resalta cómo sigue sosteniendo su integridad y significado social para la 'minoría' latina en Norteamérica. Renata Enghels y Diana Castilleja presentan un 'plan de obra' previo a los artículos, y un epílogo posterior a estos, donde sintetizan los aportes de cada trabajo de este monográfico.

La primera parte del libro comienza con "Lengua Postiza", de Giannina Braschi, e introduce al lector al dilema identitario del hablante de una lengua ajena en Estados Unidos, mientras denuncia la discriminación que sufre el inmigrante por su lengua extranjera. Oscureciendo los límites entre idioma y cultura, Braschi se encuentra en conflicto ante sus deseos de mantener su identidad, y lucha entre tener que acomodarse y encontrarse de nuevo con sus orígenes. Para ella, el español es revolucionario, incluso cuando se vive en un "país donde los extranjeros se convierten en nativos" (p. 24). Aun así, prefiere romper las reglas del juego y vivir estas dos lenguas. Concluye aludiendo a las 
próximas elecciones presidenciales, confirmando que el futuro verá a esta cultura extranjera ser más consciente de su poder, y el de su lengua.

En “'Mi Casa (Blanca) no es tu Casa (Blanca)'. El 'efecto Trump' en el español de los Estados Unidos", Silvia Betti esboza la situación demográfica, política y sociolingüística del español en los últimos años, situando la discusión en la historia reciente del español hasta el período presidencial de Donald J. Trump. Con una migración latinoamericana que data de mediados del XIX, en la actualidad Estados Unidos cuenta con 41 millones de hablantes nativos, y con otros 11,6 millones de hablantes bilingües del español.

A pesar de que esta lengua goza una presencia en espacios públicos e institucionales, la autora argumenta que Trump representa un discurso de fobia y odio al español. En su entrada al poder, el gobierno estadounidense cerró la versión en español de su página web oficial y de sus redes sociales, lo que resultó en la falta de representación y acceso a la web institucional para los habitantes de la comunidad hispana. Asimismo, Betti explica cómo Trump enmarca la identidad nacional y el patriotismo bajo el uso de una sola lengua, creando así un marco asimilacionista donde el español no tiene cabida en la construcción de la nación. El esparcimiento del español y la comunidad hispanohablante en Estados Unidos se han visto enfrentados con actos xenófobos, y, según la autora, en tiempos de Trump los "casos de odio" se han incrementado, lo que, en conjunto con los actos de intolerancia lingüística, constituyen un peligro para la expansión del español. No obstante, el español es la (segunda) lengua más estudiada en Estados Unidos. En esta situación, Betti rechaza la versión monolingüe y monolítica que Trump pretende simbolizar, y llama al lector a entender el trasfondo cultural, identitario e histórico del español.

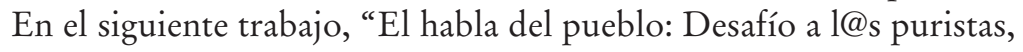
lingüistas y a Trump”, Ana Celia Zentella confecciona un manifiesto acerca de las prácticas discriminatorias que sufre la comunidad hispanohablante, apuntando a que los hispanounidenses se enfrentan a una ideología lingüística que juzga el español de los inmigrantes. La autora critica la falta de consenso de parte de ciertos lingüistas acerca de la etiqueta para el "spanglish/espanglish", proponiendo que va en desmedro de la seguridad lingüística de esta comunidad que comparte dos lenguas y dos culturas. Igualmente, denuncia cómo el gobierno estadounidense limita el acceso de la comunidad latina a una educación bilingüe, mientras se niega a traducir el himno nacional, y al uso del español en medios oficiales. Zentella propone que el pueblo latino concibe su idioma como un "frente de lucha", y que la investigación del spanglish serviría para "desafiar la reproducción de la desigualdad lingüística” (p. 42). De esta manera, llama a practicar una 'lingüística antro-política'.

En "Spanglish as an epistemological problem", capítulo con el que comienza la segunda parte de este monográfico, Ángel López García- 
Molins, ante la pregunta de si el spanglish es una mezcla de lenguas cuya gramaticalización la ha llevado a ser un dialecto de uno u otro idioma, arguye por una visión del spanglish como un dialecto poroso del español. Este proviene de un bilingüismo que propicia una anglización del español, y que debe ser estudiado también desde perspectivas psicolingüísticas. Aunque es una combinación de lenguas, no es una mezcla indeterminada de dos sistemas que constituyan una lengua híbrida, sino un proceso donde el español se ha adaptado al inglés. Por lo tanto, el spanglish es una variedad del español que ha acogido al inglés para suplir sus necesidades léxicas (y culturales), pero que mantiene su integridad, $\mathrm{y}$ un uso que es particularmente sensible al contexto.

López propone que los hablantes del spanglish muestran redes neurológicas mixtas, y que este proceso sucede entre el sistema límbico, donde se almacenarían paradigmas sintácticos del español, y la corteza cerebral, donde se encontraría un repertorio léxico en inglés y español. Esto ha conllevado una contradicción entre la conducta lingüística y la conciencia metalingüística de estos bilingües. Por un lado, los que aprenden ambos idiomas en un mismo contexto y los cambian constantemente pueden considerar tener dos sistemas distantes. Por otro lado, los bilingües que emplean anglicismos con una sintaxis española, y palabras en español en su producción en inglés, pueden considerar que controlan exclusivamente el spanglish. El autor afirma que, independientemente de la consciencia del hablante, el spanglish sucede entre la corteza y el sistema límbico, y resulta de la fluidez de ambos idiomas.

En “ ¿Existe una gramática del spanglish? Estudio de caso de la posición del adjetivo en Killer Crónicas (2004)" las autoras Renata Enghels, Laura Van y An Vende Casteele realizan un estudio que se propone examinar la naturaleza, potencialmente estable, de los sintagmas nominales que emplean cambio de código, es decir, sintagmas con sustantivos en español y adjetivos en inglés, o viceversa, a partir de un corpus escrito de ficción: Killer Crónicas de Susana Chávez-Silverman. Luego de una revisión detallada de las restricciones de las posiciones del adjetivo, tanto en contextos monolingües como bilingües, las autoras exponen distintas hipótesis para explicar los resultados obtenidos de un corpus de 356 casos de SSNN con cambio de código, dilucidando una gramática del spanglish.

Por medio de distintos análisis estadísticos y léxico-semánticos, se confirma su cuarta hipótesis, demostrando que los adjetivos de la muestra, tanto españoles $(66.7 \%)$ como ingleses $(90.1 \%)$, prefieren la anteposición. Sin embargo, los adjetivos españoles $(33.3 \%)$ se posponen con más frecuencia que los adjetivos en inglés (9.9\%). A la vez, la semántica del adjetivo español afecta la estructura de los SSNN, en cuanto los adjetivos calificativos prefieren la anteposición (71.2\%), probando que los adjetivos en español contemplan más variabilidad. Así, el SSNN del spanglish, en 
este corpus, no se entiende desde la dominancia de una lengua sobre otra, ni desde una tercera sintaxis producto de estas, sino desde un sistema que integra ambas gramáticas, establemente, y provee cierta flexibilidad al hablante para elegir elementos provenientes de ambos sistemas.

En el sexto artículo, "Dinámicas en torno al uso del español y del inglés en los Estados Unidos", Antonio Torres traza el estado del spanglish como una variedad del español difícil de definir que se desempeña en un contacto bilingüe y bicultural, cuya producción es un acto consciente con un potente valor político y simbólico. Torres explica la inherente habilidad del cerebro humano para desarrollarse en contextos multilingües, y compara las vivencias de hablantes del catalán frente otras lenguas en Europa para ilustrar como, tanto en España como Estados Unidos, el contacto es un fenómeno intergeneracional que involucra la adaptación lingüística e identitaria. En el caso del spanglish, se trata de una variedad lingüísticamente mediadora, principalmente para la segunda generación hispana en Estados Unidos.

Para explicar la distribución sociolingüística del spanglish, citando a Moreno Fernández (2017), Torres concibe a los Estados Unidos como un complejo diglósico, donde la variedad de mayor prestigio es el inglés estándar, seguido de los distintos dialectos del inglés; luego el 'español estadounidense general'; y por último el spanglish. Esta última variedad requiere un fino control lingüístico entre dos lenguas con sus propias normas de codeswitching. Sin embargo, su dependencia de una alta competencia de ambos idiomas se puede ver amenazada por un desplazamiento lingüístico ante la lengua erosionadora que es el inglés. Por lo tanto, Torres invita a reconocer la necesidad de investigar el spanglish no solo desde sus aspectos psicolingüísticos, sino también de aquellos políticos y simbólico-afectivos.

En "La especialización de funciones en el repertorio lingüístico del español de Utica, Nueva York" Juan A. Thomas estudió los contextos de uso del español formal, o norma culta estadounidense, el español popular, o spanglish, y el inglés, a partir de entrevistas a 16 hispanos que viven en Utica, entrevistados entre 2009 y 2011. El corpus también cuenta con anécdotas publicadas en periódicos locales. Esta ciudad contaba con un 11,5\% de habitantes hispanos para el 2016, donde el spanglish representa un símbolo de identidad local. Ahora bien, las dinámicas del español resultan complejas dado que el español caribeño es dominante en la ciudad, lo que dificulta la comunicación con hablantes de dialectos sudamericanos. Sin embargo, el español popular es capaz de permitir la convergencia social entre hispanos, sobre todo entre aquellos que prefieren usarlo sobre el inglés. Thomas también reporta que existe el uso de un registro formal en Utica, el cual se podría denominar 'español estadounidense general', aquel que se usa en los medios de comunicación, en situaciones institucionales, y que se considera beneficioso para el futuro laboral den- 
tro de esta comunidad. El inglés, por su lado, sigue siendo una lengua dominante en Utica. El autor explica que, como una variedad de mayor prestigio en este complejo diglósico (Moreno Fernández 2017), el inglés es necesario para acceder a servicios médicos o jurídicos, por lo que la comunidad ha acudido a servicios de interpretación, propiciando la creación de entidades dedicadas a la interpretación médica.

Enrique Serra Alegre y Sandra Moreno Guillamón presentan el último artículo del volumen que reseñamos. "Peculiaridades del espanglish" proporciona una panorámica social y lingüística de esta variedad, con el propósito de sostener que este es "un objeto de estudio poliédrico y polimórfico que demanda un acercamiento simultaneo desde enfoques diversos" (p. 132). Los autores inician su trabajo reconociendo la larga historia del spanglish, la que data de 1848 cuando México vendió 2 tercios de su territorio norteño a Estados Unidos, provocando que viejos nativos se volvieran nuevos extranjeros. En la actualidad, su práctica es un acto de rebeldía ante la dominancia del inglés, y se aprecia en los paisajes lingüísticos, los medios de comunicación y en distintas formas de arte. El spanglish ha sido polémico dentro y fuera de los círculos de la lingüística, con detractores que ven esta mezcla como una invasión del inglés, y defensores que lo reconocen como producto de la creatividad lingüística que nace de vivir dos lenguas y culturas. Sea una lengua híbri$\mathrm{da}$, un dialecto, una interferencia lingüística, o un producto del cambio de código, el spanglish representa una identidad mestiza, que incluso ha traspasado la frontera norteamericana hacia Latinoamérica. Los autores articulan que nace de un uso estratégico del lenguaje, con espacios y propósitos específicos. A la vez, proponen que en cuanto está compuesto por calcos (préstamos españolizados) y préstamos, se puede apreciar que su mutuo impacto implica la influencia de estructuras del inglés realizadas en español, de las cuales sus hablantes no son conscientes.

En definitiva, este monográfico constituye una actualización muy necesaria y clara del español en contacto con el inglés, desde sus aristas sociolingüísticas, psicolingüísticas y gramaticales. El trabajo de estos autores representa una fina descripción de un fenómeno que todavía supone interrogantes, mientras es un llamado para el lector, especializado o no, a reconocer la importancia y la complejidad de esta variedad lingüística como símbolo identitario y político en tierras norteamericanas. Sus contribuciones resultan imprescindibles para el estudiante y el académico que desee examinar este paisaje sociolingüístico.

\section{Referencias bibliográficas}

Moreno Fernández, Francisco. 2017. "Español estadounidense: perfiles lingüísticos y sociales". Glosas, 9:2. 10-23. 